\title{
Out of Asia: Mitochondrial evolutionary history of the globally introduced supralittoral isopod Ligia exotica
}

Luis A Hurtado ${ }^{\text {Corresp., }}{ }^{1}$, Mariana Mateos ${ }^{1}$, Chang Wang ${ }^{1,2}$, Carlos A Santamaria ${ }^{3}$, Jongwoo Jung ${ }^{4}$, Valiallah Khalaji-Pirbalouty ${ }^{5}$, Won Kim ${ }^{6}$

1 Department of Wildlife and Fisheries Sciences, Texas A\&M University, College Station, Texas, United States

2 Department of Biology, New York University, New York City, New York, United States

3 Biology Faculty, College of Science and Mathematics, University of South Florida, Sarasota, Florida, United States

4 Department of Science Education, Ewha Women's University, Seoul, South Korea

5 Department of Biology, Shahrekord University, Shahrekord, Iran

${ }^{6}$ School of Biological Sciences, Seoul National University, Seoul, South Korea

Corresponding Author: Luis A Hurtado

Email address: Ihurtado@tamu.edu

The native ranges and invasion histories of many marine species remain elusive due to a dynamic dispersal process via marine vessels. Molecular markers can aid in identification of native ranges and elucidation of the introduction and establishment process. The supralittoral isopod Ligia exotica has a wide tropical and subtropical distribution, frequently found in harbors and ports around the globe. This isopod is hypothesized to have an Old World origin, from where it was unintentionally introduced to other regions via wooden ships and solid ballast. Its native range, however, remains uncertain. Recent molecular studies uncovered the presence of two highly divergent lineages of $L$. exotica in East Asia, and suggest this region is a source of nonindigenous populations. In this study, we conducted phylogenetic analyses (Maximum Likelihood and Bayesian) of a fragment of the mitochondrial 16S ribosomal (r)DNA gene using a dataset of this isopod that greatly expanded previous representation from Asia and putative nonindigenous populations around the world. For a subset of samples, sequences of $12 \mathrm{~S}$ rDNA and NaK were also obtained and analyzed together with 16S rDNA. Our results show that $L$. exotica is comprised of several highly divergent genetic lineages, which probably represent different species. Most of the 16S rDNA genetic diversity (48 haplotypes) was detected in East and Southeast Asia. Only seven haplotypes were observed outside this region (in the Americas, Hawai'i, Africa and India), which were identical or closely related to haplotypes found in East and Southeast Asia. Phylogenetic patterns indicate the L. exotica clade originated and diversified in East and Southeast Asia, and only members of one of the divergent lineages have spread out of this region, recently, suggesting the potential to become invasive is phylogenetically constrained. 
1 Out of Asia: Mitochondrial evolutionary history of the globally introduced supralittoral

2 isopod Ligia exotica

4 Luis A. Hurtado ${ }^{1 *}$, Mariana Mateos ${ }^{1}$, Chang Wang ${ }^{1,6}$, Carlos A. Santamaria ${ }^{1,2}$, Jongwoo Jung ${ }^{3}$, Valiallah Khalaji-Pirbalouty ${ }^{4}$, Won $\mathrm{Kim}^{5}$

${ }^{1}$ Department of Wildlife and Fisheries Sciences, Texas A\&M University, College Station, Texas

$7 \quad 2$ Biology Faculty, College of Science and Mathematics, University of South Florida Sarasota-

8 Manatee, Sarasota, Florida 34243, USA

$9{ }^{3}$ Department of Science Education, Ewha Womans University, Seoul, Korea

$10{ }^{4}$ Department of Biology, Faculty of science, Shahrekord University, Shahrekord, Iran

115 School of Biological Sciences, Seoul National University, Seoul, Korea

$12{ }^{6}$ Present address: Department of Biology, New York University, New York, USA

$13{ }^{*}$ Corresponding author:

14 Luis A. Hurtado, Department of Wildlife and Fisheries Sciences, Texas A\&M University, Nagle 15 Hall Rm. 210, College Station, TX 77843-2258, USA.

16 Tel: +1-979-845-5777; Fax: +1-979-845-4096; E-mail: 1hurtado@tamu.edu 
18 The native ranges and invasion histories of many marine species remain elusive due to a dynamic dispersal process via marine vessels. Molecular markers can aid in identification of native ranges and elucidation of the introduction and establishment process. The supralittoral isopod Ligia exotica has a wide tropical and subtropical distribution, frequently found in harbors and ports around the globe. This isopod is hypothesized to have an Old World origin, from where it was unintentionally introduced to other regions via wooden ships and solid ballast. Its native range, however, remains uncertain. Recent molecular studies uncovered the presence of two highly divergent lineages of L. exotica in East Asia, and suggest this region is a source of nonindigenous populations. In this study, we conducted phylogenetic analyses (Maximum Likelihood and Bayesian) of a fragment of the mitochondrial 16S ribosomal (r)DNA gene using a dataset of this isopod that greatly expanded previous representation from Asia and putative nonindigenous populations around the world. For a subset of samples, sequences of $12 \mathrm{~S}$ rDNA and $\mathrm{NaK}$ were also obtained and analyzed together with $16 \mathrm{~S}$ rDNA. Our results show that $L$. exotica is comprised of several highly divergent genetic lineages, which probably represent different species. Most of the 16S rDNA genetic diversity (48 haplotypes) was detected in East and Southeast Asia. Only seven haplotypes were observed outside this region (in the Americas,

34 Hawai'i, Africa and India), which were identical or closely related to haplotypes found in East and Southeast Asia. Phylogenetic patterns indicate the L. exotica clade originated and diversified in East and Southeast Asia, and only members of one of the divergent lineages have spread out of this region, recently, suggesting the potential to become invasive is phylogenetically constrained. 
41 Numerous marine species have dispersed and established extensively throughout the world

42 via marine vessels over the past several centuries (Banks et al., 2015; Carlton, 1987; Carlton and

43 Iverson, 1981). The native ranges and invasion histories of a large number of them, however,

44 remain elusive (i.e., they are cryptogenic), as a result of one or more of the following:

45 inadequate taxonomy; poor historical documentation (particularly for older introductions);

46 presence of cryptic lineages; and multiple inputs of invaders (Carlton, 1996; Carlton, 2009). Use

47 of molecular data can greatly aid in the identification of their native ranges, cryptic diversity, and

48 of the source and recipient regions (Geller et al., 2010).

49 The supralittoral isopod Ligia exotica Roux, 1828 represents a case of a widespread

50 cryptogenic taxon with an old, albeit poorly documented, history of human-assisted dispersal

51 (recognized as exotic in the type locality since its original description), as well as a highly

52 problematic taxonomy. Commonly known as wharf roach, this isopod has a wide tropical and

53 subtropical distribution, and is considered an alien species in different regions of the world,

54 where it is frequently found in harbors, and ports, and other man-made structures (Schmalfuss,

55 2003; Taiti et al., 2003; Van Name, 1936; Yin et al., 2013). Similarly to the other coastal

56 members of Ligia, L. exotica is a direct developer (i.e., lacks a planktonic larval stage; a feature

57 of peracarids) that occupies a narrow vertical range between the supralittoral and the waterline,

58 mainly occurring on rocky substrates (Hurtado et al., 2010; Santamaria et al., 2013). The

59 present-day broad distribution of L. exotica, including all continents except Europe and

60 Antarctica, suggests that it possesses unique invasive capabilities within Ligia. With the

61 exception of Ligia oceanica, an endemic of the Atlantic coast of Europe that has been introduced

62 into some localities in the northern Atlantic coast of the US (Richardson, 1905), all other coastal 
63 species of Ligia ( 30) do not appear to have been moved by humans, or at least not to as many

64 geographically distant places as L. exotica (Schmalfuss, 2003).

65 An Old World origin has been proposed for L. exotica (Fofonoff et al., 2017; Van Name,

66 1936), from where it would have been unintentionally moved around the world on wooden ships

67 and solid ballast (Griffiths et al., 2011; Van Name, 1936). Ligia exotica was originally described

68 by Roux (1828) from docks in Marseille (France), within the range of its congener L. italica, a

69 species that is native and broadly distributed throughout the Mediterranean basin (Schmalfuss,

70 2003). Roux (1828) reasoned that a ship had likely transported this isopod from Cayenne,

71 French Guiana (South America). Remarkably, L. exotica did not become established in the

72 Mediterranean, and there are no other records of its presence in this well studied basin (Cochard

73 et al., 2010; Fofonoff et al., 2017; Roman, 1977). Roux's description places the first record of

74 introduction of L. exotica at 189 years before present, but its introduction history would be older

75 if his assertion that it was introduced from South America is correct, because this region is not

76 regarded part of its native range. Consequently, L. exotica represents one of the oldest

77 documented introductions for a marine organism. A database of 138 other coastal marine

78 invertebrate species non-native to either Australia, New Zealand, or the United States (Byers et

79 al., 2015), indicates that only two other species have older documented introduction times: the

80 green crab Carcinus maenas in 1817 (Say, 1818); and the hydrozoan Cordylophora caspia in

811799 (Byers et al., 2015).

82 Ligia exotica is also absent from the Atlantic coasts of Europe, where its congeneric $L$.

83 oceanica is native and widely distributed. For this region, there is only a 1936 report of a $L$.

84 exotica specimen found in a house in Amsterdam (Fofonoff et al., 2017; Holthuis, 1949). In

85 addition, although a specimen assigned to L. exotica was collected on Sao Miguel Island 
86 (Azores) in 1905 (Fofonoff et al., 2017), this isopod has not become established in this

87 archipelago, where the two European species, L. oceanica and L. italica, are present (Cardigos et 88 al., 2006).

89 In the New World, L. exotica has a broad distribution along the Atlantic coast from New 90 Jersey (US) to Montevideo (Uruguay), including the Gulf of Mexico (Mulaik, 1960; Schultz,

91 1977; Schultz and Johnson, 1984). Collections of L. exotica in the US Atlantic, eastern Gulf of

92 Mexico, Brazil, and Uruguay date back to the 1880's; whereas records in the western Gulf of

93 Mexico date back to the first half of the 20th century (Fofonoff et al., 2017; Richardson, 1905;

94 Van Name, 1936). In this region, two species have been synonymized with L. exotica: Ligia 95 grandis Perty, 1834 from Brazil; and Ligia olfersii Brandt, 1833 from Florida to Brazil, 96 including the Gulf of Mexico (Schmalfuss, 2003). In addition, the Caribbean-endemic Ligia 97 baudiniana Milne Edwards, 1840 appears to have been described based on individuals of $L$. 98 exotica collected in Veracruz, Mexico (reviewed in Santamaria et al., 2014), and the two species 99 have been confused (i.e., Ligia exotica var. hirtitarsis Dollfus, $1890=$ L. baudiniana; 100 Schmalfuss, 2003).

101 Although L. exotica has been reported in the Pacific coast of the Americas, from the Gulf of 102 California, Mexico, to Punta Arenas, Chile (Van Name, 1936), this species appears to be absent 103 in this coast (Fofonoff et al., 2017). Ligia exotica may have been confused with L. occidentalis, 104 a species native to the Gulf of California and the Eastern Pacific region between the Baja 105 Peninsula and southern Oregon, which appears to correspond to a cryptic species complex (Eberl 106 et al., 2013; Hurtado et al., 2010). Despite being reported in the Gulf of California (Mulaik, 107 1960; Richardson, 1905), L. exotica was not found during a comprehensive Ligia collecting 108 effort along the shores of this basin and adjacent regions (Hurtado et al., 2010). Ligia 
109 gaudichaudii Milne Edwards, 1840, which according to its original description "seems to come

110 from the coasts of Chile", has been synonymized with L. exotica, but its original locality is

111 uncertain.

112 In Hawai' 'i, L. exotica was first reported in 1996, and previous records of this isopod in the

113 archipelago correspond to L. hawaiensis, an endemic species (Eldredge and Smith, 2001).

114 Although it may be present in other Polynesian islands (Fofonoff et al., 2017), the Indian and

115 Pacific Ocean harbor a number of very similar species that have been morphologically assigned

116 to L. exotica, but may correspond to different species (Schmalfuss, 2003; Van Name, 1936). In

117 Australia, L. exotica is regarded as introduced in the southeastern coast, and cryptogenic in the

118 northern coast (Dalens, 1993; Fofonoff et al., 2017; Green, 1962). In Africa, L. exotica has been

119 reported at multiple localities. It is considered introduced into the Atlantic west-central coast

120 and South Africa, and possibly native in the eastern coast of the continent, where it is reported

121 from Sudan to Mozambique, including Madagascar (Ferrara and Taiti, 1979; Fofonoff et al.,

122 2017; Griffiths et al., 2011; Roman, 1977).

123 The region spanning East Asia to the southern tip of India is also suggested to be part of the

124 native range of L. exotica (Fofonoff et al., 2017). Molecular studies in East Asia report cryptic

125 diversity for this isopod and propose this region as a source of introduced populations. Jung et

126 al. (2008) re-assessed the previously reported (Kwon, 1993) occurrence of L. exotica in South

127 Korea, by conducting molecular phylogenetic analyses of a fragment of the mitochondrial $16 \mathrm{~S}$

128 ribosomal (r)DNA gene from individuals sampled along the South Korean coast, as well as

129 previously reported sequences of $L$. exotica from two putative non-native populations in the US

130 (i.e., Georgia and the Hawaiian island of O'ahu). They found two highly divergent clusters in

131 South Korea: the "eastern group", which includes haplotypes occurring mainly along the eastern 
132 and southeastern coastlines of South Korea; and the "western group", which includes haplotypes

133 occurring mainly along the western and southwestern coastlines of South Korea. These two

134 lineages were in turn highly divergent from the lineage comprised of the US haplotypes. Jung et

135 al. (2008) suggested that the "western group, "eastern group", and the L. exotica lineage from the

136 US, each represents a distinct species, and that L. exotica appeared to be absent from South

137 Korea. Their understanding on the phylogenetic relationships among the three lineages was

138 limited, however, due to the lack of outgroups in their dataset.

139 Yin et al. (2013) conducted morphological and phylogenetic analyses of Ligia specimens

140 sampled throughout the northeastern coastline of China. Their phylogenetic analyses also

141 included the sequences examined by Jung et al. (2008), and used several distant taxa as

142 outgroups. They found two highly divergent genetic lineages, and examination of traditional

143 morphological characters indicated that one corresponded to L. exotica and the other to Ligia

144 cinerascens Budde-Lund, 1885. The "eastern group" sequences of South Korea, and those of

145 Georgia and O'ahu, clustered within the L. exotica clade, whereas the "western group" sequences

146 of South Korea clustered within the L. cinerascens clade. Within the L. exotica clade, two highly

147 divergent lineages were observed, one of which contained the samples from Georgia and O'ahu,

148 leading Yin et al. (2013) to suggest that East Asia was a source of introduced L. exotica

149 populations.

150 Examination of $L$. exotica from other putative native localities, as well as from additional

151 putative introduced populations, is needed to assess whether this isopod harbors additional

152 molecular diversity, and to better understand its evolutionary and invasion history. An extensive

153 dataset of Ligia sp. 16S rDNA sequences from Southeast to East Asia that have not been

154 included in any published analysis is available in GenBank. Herein, we report phylogenetic 
155 analyses of these sequences, the ones reported for L. exotica and L. cinerascens from published 156 studies, and new sequences obtained from specimens of these isopods in the Americas, Hawai' $i$, 157 Africa, and Asia. Phylogenetic analyses of a subset of samples were also conducted for the 158 mitochondrial $12 \mathrm{~S}$ rDNA and nuclear NaK genes. We conducted phylogenetic analyses to: (1) 159 establish whether the new sequences from Asia belong to the L. exotica or L. cinerascens clades;

160 (2) determine whether further molecular diversity is found in these clades; and (3) shed light on 161 the evolutionary and invasion history of L. exotica. 


\section{MATERIAL AND METHODS}

\section{$163 \quad 2.1$ Sampling}

164 Specimens assigned to L. exotica were obtained from 42 localities around the world (Figure

165 1; Table S1). We also obtained specimens assigned to L. cinerascens (from East Asia), which

166 was used as an outgroup in the phylogenetic reconstructions. Phylogenetic analyses including

167 most Ligia species (unpublished; LAH) indicate that L. cinerascens is sister to the L. exotica

168 clade. Yin et al. (2013) also found a sister relationship between L. exotica and L. cinerascens, in

169 a dataset that also included L. occidentalis, and used L. oceanica and Idotea baltica (Idoteidae)

170 as outgroups. The use of $L$. cinerascens as the only outgroup enabled the retention of a higher

171 number of confidently-aligned characters and less homoplasy, which should enhance resolution

172 within the L. exotica clade. Specimens were preserved in $70-100 \%$ ethanol. In addition to the

173 above specimens, we used publicly available sequences (see below and in Table S1).

174

175

\subsection{DNA extraction, PCR, and sequencing}

176 Total genomic DNA was isolated from pleopods or legs of Ligia specimens with the DNeasy

177 Blood \& Tissue kit (Qiagen Inc., Valencia, CA) following the manufacturer's protocol. Due to

178 its relative ease of amplification in Ligia and phylogenetic signal, numerous studies, including

179 those of L. exotica, have reported 16S rDNA gene sequences. To maximize the number of

180 publicly available records that could be compared, we targeted a $\sim 490$-bp region of the $16 \mathrm{~S}$

181 rDNA gene, which was amplified with published primers 16Sar (5’-

182 CGCCTGTTTATCAAAAACAT-3') and 16Sbr (5'-CCGGTCTGAACTCAGATCACGT-3')

183 (Palumbi, 1996). Each PCR reaction contained 1-3 $\mu$ l DNA template, $0.5 \mu$ l each primer (10

184 pmol), $0.1 \mu \mathrm{l}$ Taq DNA polymerase (5,000units/ $\mu \mathrm{l}), 0.5 \mu \mathrm{l} \mathrm{dNT}$ s $(10 \mathrm{mM})$, and $2.5 \mu \mathrm{l} 10 \times$ PCR 
185 buffer (15 mM MgCl $2,500 \mathrm{mM} \mathrm{KCl}, 100 \mathrm{mM}$ Tris-HCl, $\mathrm{pH}$ 8.3). PCR conditions used were: 4

$186 \mathrm{~min}$ at $94^{\circ} \mathrm{C}$ followed by 30 cycles of $1 \mathrm{~min}$ at $94^{\circ} \mathrm{C} ; 30 \mathrm{~s}$ at $49^{\circ} \mathrm{C}, 1.5 \mathrm{~min}$ at $72^{\circ} \mathrm{C}$; and a final

187 extension at $72^{\circ} \mathrm{C}$ for $4 \mathrm{~min}$. PCR products were cycle sequenced at the University of Arizona

188 Genetics Core (UAGC).

189 For a subset of individuals (see Table S1), we also amplified and sequenced a 495-bp

190 fragment of the 12S rDNA gene (primers crust-12Sf/crust-12Sr; Podsiadlowski and

191 Bartolomaeus, 2005) and a 709-bp fragment of the nuclear locus sodium-potassium ATPase $\alpha$ 192 subunit $(\mathrm{NaK})$ (primers NaK-for-b and NaK-rev2; Tsang et al., 2008).

193

$194 \quad$ 2.3 Datasets and sequence alignment

195 Sequencher 4.8 (Genecodes, Ann Arbor, MI) was used to assemble the new sequences and

196 trim the primer regions. We also included all 16S rDNA sequences of $L$. exotica and $L$.

197 cinerascens reported in Jung et al. (2008) and Yin et al. (2013), as well as 16S rDNA sequences

198 of specimens identified as Ligia sp. or L. exotica from Asia available in GenBank, but not

199 incorporated into a published study (Table S1). When present, primer regions were also

200 removed from GenBank sequences.

201 All sequences were aligned in MAFFT v.7 (Katoh, 2013) online using the Q-INS-I strategy, 202 which considers the secondary structure of RNA, with default parameters (e.g., gap opening 203 penalty $=1.53$ ). Unique haplotypes were identified on the basis of absolute pairwise distances 204 calculated with PAUP v.4.0b10 (Swofford, 2002), and redundant sequences were removed from 205 analyses. Gblocks 0.91b (Castresana, 2000; Talavera and Castresana, 2007) was used to identify 206 positions with questionable homology that were removed prior to phylogenetic analyses. The 207 following GBlocks parameters were used: "Minimum Number Of Sequences For A Conserved 
208 Position" $=50 \%$ of the number of sequences +1 (i.e., 42); "Minimum Number Of Sequences For

209 A Flank Position" $=85 \%$ of the number of sequences (i.e., 70); "Maximum Number Of

210 Contiguous Nonconserved Positions" = 4 or 8; "Minimum Length Of A Block" = 5 or 10; and

211 "Allowed Gap Positions" = half. In addition to the 16S rDNA only dataset, we examined a

212 dataset of 23 taxa containing the concatenated 16S rDNA and 12S rDNA genes.

213

$214 \quad 2.4$ Phylogenetic analyses

215 To determine the most appropriate model of DNA substitution, jModelTest v.2.1.4 (Darriba 216 et al., 2012) was used to calculate likelihood scores among 88 candidate models for 16S rDNA

217 gene, based on the fixed BIONJ-JC tree under the Akaike Information Criterion (AIC), corrected 218 AIC (AICc), and the Bayesian Information Criterion (BIC). The best model selected by the BIC 219 was employed in phylogenetic analyses, except in the following two cases. First, if the selected 220 model was not available in the specific Maximum Likelihood (ML) or Bayesian Inference (BI) 221 program, the next most complex model was implemented. Second, considering the potential 222 problems associated with using two parameters, a proportion of invariable sites (I) and a Gamma 223 distribution of rates among sites $(\Gamma)$, simultaneously in the model [see RAxML manual and 224 (Yang, 2006)], we chose the simpler $\Gamma$ if the best model included both $I$ and $\Gamma$ parameters.

225 For the ML analyses, the CIPRES (Miller et al., 2010) implementations of RAxML v. 8.2.10 226 (Stamatakis, 2014) and GARLI v.2.01 (Zwickl, 2006) were used. RAxML executed 1,000

227 bootstrap replicates with a thorough ML search under the standard non-parametric bootstrap 228 algorithm and the GTR $+\Gamma$ model, whereas GARLI implemented 1,000 bootstrap replicates, the 229 BIC selected model, and all other settings as default. The majority-rule consensus trees for each 230 analysis were calculated using the SumTrees command of DendroPy v.3.10.1 (Sukumaran and 
231 Holder, 2010). A third ML bootstrap analysis was conducted with PhyML v3.0_360 (Guindon

232 and Gascuel, 2003) as implemented in a public server

233 (http://phylogeny.lirmm.fr/phylo_cgi/one task.cgi?task type=phyml).

234 For Bayesian Inference (BI), MrBayes v.3.2.6 (Huelsenbeck and Ronquist, 2001; Ronquist

235 and Huelsenbeck, 2003; Ronquist et al., 2012) as implemented in CIPRES, and Phycas v.1.2.0

236 (Lewis et al., 2005a) implemented locally, were employed. To alleviate the unpredictable

237 behavior in Bayesian analysis when dealing with hard polytomies (i.e., "star-tree paradox"),

238 which can lead to arbitrary resolutions and overestimation of posterior probabilities (Alfaro and

239 Holder, 2006; Kolaczkowski and Thornton, 2006; Lewis et al., 2005b; Suzuki et al., 2002; Yang

240 and Rannala, 2005), an analysis employing a polytomy prior was implemented in Phycas [see

241 Phycas manual and Lewis et al. (2005b)]. The following criteria were used to determine if the

242 Bayesian analyses had reached convergence, and if an adequate sample of the posterior had been

243 generated: (a) the posterior probability values tended to be stable; (b) AWTY (Nylander et al.,

244 2008; Wilgenbusch et al., 2004) exhibited a high correlation between the split frequencies of

245 independent runs; (c) the average standard deviation of the split frequencies of independent runs

246 became stable and approached zero; (d) Potential Scale Reduction Factor (PSRF), a convergence

247 diagnostic obtained after summarizing the sampled parameter values in MrBayes, was close to

248 one; and (e) the Effective Sample Size (ESS) for the posterior probabilities evaluated in Tracer

249 v.1.6 (Rambaut et al., 2014) exceeded 200. Samples prior to reaching stationarity were

250 eliminated as "burn-in". The posterior probability for each node was estimated by computing a

251 majority-rule consensus of post-burnin tree samples using the SumTrees command (Sukumaran

252 and Holder, 2010). 
253 Given the low number of alleles and shallow genetic divergences found within the clade 254 involving haplotypes detected in putative introduced populations (see Results; i.e., Clade D in 255 Figure 2), we also conducted a maximum parsimony branch and bound search in PAUP* 256 v.4.0a149 (Swofford, 2002) for this clade. Ambiguous character optimization was achieved by 257 the accelerated transformation (ACCTRAN) algorithm. The conservative estimate of pairwise 258 genetic distances with Kimura-2-parameter (K2P) correction was calculated with PAUP* 259 v.4.0a149 (Swofford, 2002). 


\section{RESULTS}

\section{3.1 Model Selection}

263 For $16 \mathrm{~S}$ rDNA, a total of 97 sequences of the L. exotica clade and 41 of the L. cinerascens 264 clade were examined (Table S1). The final 16S rDNA gene dataset excluding redundant 265 sequences consisted of 81 taxa (51 in the L. exotica clade and 30 in the L. cinerascens clade). 266 After alignment, a total of 454 characters (out of 488) were retained, for which homology was 267 reliable, and 97 of these were parsimony informative. jModelTest selected a complex model 268 (i.e., TPM2uf) with five substitution parameters (see jModelTest manual), $+\mathrm{I}$, and $+\Gamma$ according 269 to the AIC (weight $=0.2607)$ and AICc (weight $=0.3509)$, and a relatively simple model (i.e., 270 HKY) with two substitution parameters (see jModelTest manual), $+\mathrm{I}$, and $+\Gamma$ according to the 271 BIC (weight $=0.3183)$. Similarly, the best model selected for the $16 \mathrm{~S}$ rDNA+12S rDNA 272 concatenated dataset was also TPM2uf $+\mathrm{I}+\Gamma(\mathrm{BIC}$ weight 0.31$)$. When applicable in the 273 different programs used, the exact models selected by the three criteria were implemented. In 274 addition, we implemented the GTR $+\Gamma$ model, which was included in the $99.9 \%$ cumulative 275 weight interval of all selection criteria, in all of the methods, to assess the sensitivity of clade 276 support values to variations in the substitution model (Table S2).

\subsection{Phylogenetic Results}

In general, the use of different substitution models or priors yielded similar overall topologies 280 of phylogenetic trees, although some discrepancies, reflected in node support values (Figure 2812 ; Table S3), were observed among different approaches. Our phylogenetic reconstructions 282 (Figure 2) recovered a highly supported split [Bootstrap Support (BS): 98-100; Posterior 283 Probability (PP): 100] between L. exotica and L. cinerascens. The L. cinerascens clade is 
284 restricted to the northern part of East Asia, in the western coast of South Korea, Honshu and

285 Hokkaido in Japan, and northeastern China. Maximum K2P divergence observed within this

286 clade was $2.9 \%$ (Table 1). The NaK gene was obtained for 20 individuals representing most of

287 the main lineages of the L. exotica clade (see Table S1; Figure 2), as well several individuals

288 assigned to L. cinerascens. Three fixed differences were detected between the L. exotica clade

289 and L. cinerascens, but no variation within them was found.

290 Our analyses revealed 23 new 16S rDNA haplotypes within the L. exotica clade (marked

291 with triangles in Fig. 2) that were not reported in the previous studies of Jung et al. (2008) and

292 Yin et al. (2013). The L. exotica clade was divided into four main lineages (named A, B, C, and

293 D). Node support for different datasets (i.e., 16S rDNA alone and 16S rDNA + 12S rDNA),

294 methods and substitution models is shown in Table S3, and summarized in Fig. 2. In general, the

295 main clades (B, C, and D) received high support from all analyses except the ML analyses of the

296 16S rDNA dataset alone (see Fig. 2). Divergences between and within main lineages are shown

297 in Table 1 . At the base of the L. exotica clade, a relatively distant $(\mathrm{K} 2 \mathrm{P}$ divergence $=9.8-$

298 13.2\%) lineage from Kanagawa, Japan (A) diverged from a clade that contains the remaining

299 lineages (clade $\mathrm{B}+\mathrm{C}+\mathrm{D}$; high support from all analyses except ML of $16 \mathrm{~S}$ rDNA). Within the

300 latter clade, a basal split (K2P divergence $=7.3-11.6 \%)$ is observed between a lineage consisting

301 mainly of samples from temperate regions in East Asia (clade B; maximum within-clade K2P

302 divergence $=2.0 \%$ ) and a clade (i.e., $\mathrm{C}+\mathrm{D})$ containing the remaining lineages. Some of the

303 populations in Clade B have overlapping distributions with L. cinerascens in China (e.g. Tianjin

304 and Shandong) and the western coastline of South Korea (e.g. Boryeong) (Fig. 1). Within the

305 clade $\mathrm{C}+\mathrm{D}$, a basal divergence $(\mathrm{K} 2 \mathrm{P}=6.7-9.2 \%)$ is observed between a lineage from Okinawa,

306 Japan (C), which contains two highly divergent lineages from this island (6.3\% K2P divergence), 
307 and a clade (D) with the remaining samples (maximum within-clade K2P divergence $=4.6 \%$ ).

308 Within clade D, several lineages are distinguished. The first (D1 in tree) is restricted to East

309 Asia localities (maximum within-clade K2P divergence = 1.3\%; support from ML was weak).

310 The second (D2) has haplotypes found in East Asia, but also in introduced populations from

311 Hawai'i, Brazil, and Uruguay (maximum within-clade K2P divergence $=0.9 \%$; well supported

312 by all methods). The remaining haplotypes formed a clade with a subset of the methods, but

313 support was weak. We have therefore collapsed it in Figure 2, but labeled all these haplotypes as

314 belonging to haplogroup "D3" (maximum within-haplogroup K2P divergence = 1.1\%).

315 Haplogroup "D3" has haplotypes observed in putative introduced populations from the Gulf of

316 Mexico, Trinidad, Brazil, Uruguay, South Africa, Mozambique, and is also found in South to

317 East Asia (see Discussion for considerations of native range and introduced populations).

318 Figure 3 shows a strict consensus unrooted parsimony tree (made of the 18 most

319 parsimonious trees; CI excluding uninformative characters $=0.8421 ; \mathrm{RI}=0.9552$ ) for clade $\mathrm{D}$

320 (i.e., the only clade found to contain haplotypes found in putative introduced populations). The

321 three previously described main lineages within this clade are represented by different haplotype

322 colors (i.e., D1 green circles, D2 light blue circles, and "D3” dark blue circles). Seven

323 haplotypes were observed in putative introduced populations (see Discussion), three within D2

324 and four within "D3" (denoted by stars). "D3" contains the haplotype that was most common in

325 introduced populations of the Gulf of Mexico, and was also found in the US Atlantic coast

326 (Georgia), Trinidad (Chaguaramas Bay), Brazil (Ilha Grande, Rio de Janeiro), Uruguay, and

327 Cambodia. Another D3 haplotype was found in Mexico (Veracruz), Trinidad (Chaguaramas

328 Bay), and South Africa, but was not observed in Asia. A third haplotype was observed in

329 Mozambique, which likely represents another introduced population, and in India. The fourth 
330 putatively introduced D3 haplotype was only observed in South Africa. Within D2, a haplotype 331 was found in O'ahu (Pearl Harbor) and Hawai'i Island, which was also observed in Japan and

332 Taiwan. Another D2 haplotype was found exclusively in O'ahu (Honolulu Harbor). Finally, a 333 third D2 haplotype was observed in Brazil (Praia de Calhetas, Cabo de Santo Agostinho, 334 Pernambuco), Uruguay, as well as in Taiwan. 


\subsection{Multiple divergent lineages and taxonomic uncertainty}

338

The L. exotica clade is comprised of highly divergent lineages, which probably represent multiple species. Using morphological characters (i.e., number of segments in the second antenna flagellum, uropod, characters of the telson and the shape of the appendix masculina on

341 the second pleopod of adult males), Yin et al. (2013) concluded that members of clades B and D

342 in our phylogenetic tree correspond to L. exotica (they did not examine members of clades A and 343 C). Thus, it is possible that cryptic diversity occurs within the L. exotica clade. High levels of 344 cryptic diversity have been reported in numerous studies of Ligia and other intertidal isopods 345 regarded as single broadly distributed species (Hurtado et al., 2013; Hurtado et al., 2017;

346 Hurtado et al., 2016; Hurtado et al., 2010; Santamaria et al., 2017b; Santamaria et al., 2016;

347 Santamaria et al., 2014; Santamaria et al., 2013).

348 Some of the lineages within the L. exotica clade, however, may correspond to species that 349 have been described in the East Asia region. For example, our Clade C samples, from Okinawa 350 and Kitadaito, may correspond to Ligia ryukyuensis Nunomura, 1983, described from the

351 Ryukyu Islands (Nunomura, 1983), and/or Ligia daitoensis Nunomura, 2009, described from the 352 Daito Islands (Nunomura, 2009). Similarly, our sample from Kanagawa (Clade A) may 353 correspond to Ligia yamanishii Nunomura, 1990 described from the Tokyo Prefecture 354 (Nunomura, 1990). South of Kaganawa, Ligia miyakensis Nunomura, 1999 and Ligia 355 hachijoensis Nunomura, 1999 are also reported, both described from the Izu Islands (Nunomura, 356 1999); and Ligia boninensis Nunomura, 1979, described from the Bonin Islands (Nunomura, 357 1979), south of the Izu Islands. Schmalfuss (2003) indicates, however, that the description of $L$. 358 miyakensis does not allow separation from L. exotica, and that L. hachijoensis is possibly 
359 conspecific with L. exotica. Unfortunately, the condition of our specimens precluded adequate

360 examination of their morphology, and future work is needed to determine whether some of our

361 lineages represent these species. Given the taxonomic uncertainty, and to facilitate the

362 discussion of our results, however, we refer to lineages A, B, C, and D collectively as the $L$. 363 exotica clade.

364

365

\subsection{Native range and introduced populations}

The observed phylogenetic patterns support an origin and long evolutionary history of the $L$. exotica clade in the East and Southeast Asia region. Its sister relationship with L. cinerascens, also distributed in East Asia, suggests that their ancestor occupied, and diversified within, this region. Furthermore, a long evolutionary history of the L. exotica clade within this region is also supported by the numerous diversification events that led to highly divergent lineages, all of which, except for seven haplotypes within clade D, are only found in this region. Clade D exhibits much higher genetic diversity within the East and Southeast Asia region than in all other sampled regions collectively (i.e., the Americas, Hawai'i, Africa and India), where only seven out of the 25 16S rDNA haplotypes found in clade D were detected. Three of these seven haplotypes were also observed in East and Southeast Asia. The other four, albeit not detected in this region, were only separated by few substitutions (1-3 mutational steps away) from haplotypes found in East and Southeast Asia, and it is possible that we failed to sample them in this region (individuals from Veracruz, which had one of these four haplotypes have also the same 12S rDNA haplotype found in an individual from Taiwan). Therefore, our results suggest the L. exotica clade originated and diversified in East and Southeast Asia, and that recently, 
381 relative to the diversification observed in this clade, members of Clade D have spread out of this 382 region.

383 Although South Asia and the eastern coast of Africa have been suggested to be part of the 384 native range of L. exotica (Fofonoff et al., 2017), it is likely that the L. exotica populations 385 distributed there are introduced. Only one 16S rDNA haplotype was observed in these two 386 regions, which was not found in East and Southeast Asia, but is only separated by two nucleotide 387 differences from one observed in China. Finding the same haplotype between these two distant 388 regions (the distance between the localities in Mozambique and India is $\sim 6,000 \mathrm{Km}$ ) suggests 389 that the specimens from Mozambique, at least, are non-native. South Asia and the eastern coast 390 of Africa harbor endemic species or lineages of other Ligia species, and species in the Indian 391 Ocean have often been misidentified as L. exotica (Schmalfuss, 2003; Taiti, 2014). Ligia 392 exotica, thus, may not be as common as previously thought in these regions, and scattered 393 isolated introduced populations might occur within the range of native lineages, as observed in 394 the Caribbean (see below). South Asia is home to Ligia dentipes Budde-Lund, 1885, which has 395 a broad distribution that spans the Nicobar Islands, Andaman Islands, Maldives, Seychelles, Sri 396 Lanka, and Thailand (Santamaria et al., 2017b; Taiti, 2014). Three divergent (12-15\% 397 divergence at the COI gene) lineages of L. dentipes were detected in a study that surveyed the 398 Seychelles, Sri Lanka, and Thailand (Santamaria et al., 2017b). Similarly, the eastern coast of 399 Africa harbors two highly divergent lineages of Ligia vitiensis (Dana, 1853), one distributed in 400 Tanzania, Seychelles, and Madagascar, and the other in Tanzania (Santamaria et al., 2017b). 401 Other species reported in East Africa, but lacking molecular data, are: Ligia ferrarai 402 Kersmaekers \& Verstraeten, 1990 in Madagascar; Ligia pigmentata Jackson, 1922 in Somalia 403 [also reported in the Red Sea and Persian Gulf; although records for this last basin have been 
404 questioned (Khalaji-Pirbalouty and Wägele, 2010)]; and Ligia malleata Pfeffer, 1889 in

405 Tanzania, which is possibly a synonym of L. exotica (Schmalfuss, 2003).

406 Ligia exotica is considered introduced in South Africa (Griffiths et al., 2011), where we

407 found two haplotypes, differing at a single nucleotide position from each other, belonging to

408 haplogroup "D3". One of these haplotypes was also observed in Mexico and Trinidad. Three

409 species of Ligia are native to South Africa: Ligia dilatata Brandt, 1833 (also reported in

410 Namibia); Ligia glabrata Brandt, 1833 (also reported in Namibia); and Ligia natalensis Collinge,

4111920 (Schmalfuss, 2003). These species appear to have a long evolutionary history in South

412 Africa (Greenan et al., 2017). Ligia exotica populations in the Atlantic west-central coast of

413 Africa are also considered introduced, although genetic studies would be useful to verify species

414 identity (Fofonoff et al., 2017). Ligia exotica also does not appear to be native in Southwest

415 Asia, and there is doubt about reports of this isopod in the Red Sea (Khalaji-Pirbalouty and

416 Wägele, 2010). The region has several endemic Ligia species reported: Ligia dioscorides Taiti

417 \& Ferrara, 2004 from the Socotra Archipelago in Yemen; Ligia persica Khalaji-Pirbalouty \&

418 Wägele, 2010 from the Persian Gulf; and Ligia yemenica Khalaji-Pirbalouty \& Wägele, 2010

419 from the Gulf of Aden (Khalaji-Pirbalouty and Wägele, 2010).

420 Pacific populations outside East and South East Asia are also likely introduced. One of the

421 two L. exotica haplotypes found in Hawaii was also observed in East Asia (Taiwan and Japan),

422 and the other one differs at a single nucleotide position. As in the Indian Ocean, a number of

423 different species in the Pacific Ocean may have been wrongly assigned to L. exotica

424 (Schmalfuss, 2003; Van Name, 1936). Although we did not examine individuals from Australia,

425 it is likely that populations of L. exotica in this continent are also introduced. Two endemic

426 species are reported there: Ligia australiensis Dana, 1853, which is widely distributed in the 
427 coast of Australia, including Tasmania and Lord Howe Island; and, Ligia latissima (Verhoeff, 428 1926), endemic to New Caledonia (Schmalfuss, 2003). Future work is needed to genetically 429 characterize native and non-native Ligia from Australia. Interestingly, despite reports of the 430 occurrence of L. exotica in the Gulf of California (Mulaik, 1960; Richardson, 1905), we failed to 431 find it during extensive surveys of this and the adjacent regions (Eberl et al., 2013; Hurtado et 432 al., 2010). Although it is possible that L. exotica occurs in hitherto unsampled Pacific coast 433 localities of the New World, it is likely that past records of this species were misidentifications 434 of the morphologically similar species L. occidentalis.

435 In the Americas, Ligia exotica is very common in the US Atlantic coast, Gulf of Mexico, and 436 the coastal region between Brazil and Argentina, where other Ligia species are rare or absent. 437 Records of L. exotica in the US Atlantic, eastern Gulf of Mexico, Brazil and Uruguay date back 438 to the 1880's, and in the western Gulf of Mexico to the first half of the 20th century (Fofonoff et 439 al., 2017; Richardson, 1905; Van Name, 1936). Within the Gulf of Mexico (a mostly sandy 440 coastline), jetties and other man-made structures have provided suitable habitats for this isopod 441 throughout the basin (Schultz and Johnson, 1984). Most of this basin is devoid of other Ligia 442 species, with the exception of a few localities in Florida and Yucatán, where L. baudiniana is 443 present (Santamaria et al., 2017a; Santamaria et al., 2014; Hurtado unpublished). Ligia exotica 444 exhibits very low genetic diversity in this region, with a single 16S rDNA haplotype observed, 445 except for Veracruz, where a different closely related haplotype was detected (both from the 446 "D3" haplogroup). The most common haplotype was also observed in Georgia, in the Atlantic 447 coast of the US, where L. exotica is also broadly distributed from New Jersey to Florida in the 448 absence of other Ligia, with the exception of the southern tip of Florida where L. baudiniana is 449 also reported (Schultz and Johnson, 1984). 
In the Caribbean, we found L. exotica only in a small pile of rocks in a little harbor in

451 Trinidad, despite a major sampling effort for Ligia that included different countries in the region,

452 where the widely distributed native L. baudiniana was mainly recovered (Santamaria et al.

453 2014). Two haplotypes were found in Trinidad, one was also observed in Veracruz, Mexico, and

454 South Africa, whereas the other was also observed in the Atlantic US, Gulf of Mexico, Brazil,

455 Uruguay, and Cambodia. It is possible that some of the previous reports of L. exotica in the

456 Caribbean correspond to misidentifications, as this species has been confused with L. baudiniana

457 (Santamaria et al., 2014; Schmalfuss, 2003; Van Name, 1936).

458 In the Atlantic coast between Brazil and Argentina L. exotica appears to be broadly

459 distributed (Schmalfuss, 2003) in the absence of native Ligia [although L. baudiniana has been

460 reported in Rio de Janeiro (Van Name, 1936), this needs to be confirmed; we only found $L$.

461 exotica at this and a nearby locality]. We sampled five localities in this region and found one

462 haplotype from clade D2 (also found in Taiwan) and one from haplogroup "D3" (identical to the

463 most common haplotype found in the Gulf of Mexico). The presence of two divergent

464 haplotypes (separated by 16 nucleotide differences at the 16S rDNA gene) suggests independent

465 introductions have occurred in this region. Both haplotypes can co-occur in close sympatry. In

466 Uruguay, the two haplotypes were observed in specimens collected concurrently from the same

467 rock.

468

469 4.3 Phylogeographical patterns in East and Southeast Asia

470 Occurrence of multiple genetically divergent lineages within the L. exotica clade in East and

471 South East Asia is similar to the phylogeographic patterns observed in the following recognized

472 species of Ligia, whose distribution includes or is limited to tropical and/or subtropical coasts of 
473 other regions: L. occidentalis, whose range spans the Pacific coast between central Mexico and

474 southern Oregon, including the Gulf of California (Eberl et al., 2013; Hurtado et al., 2010); L.

475 baudiniana in the Caribbean and a small Pacific region between Central and South America

476 (Santamaria et al., 2014); L. hawaiensis in the Hawaiian archipelago (Santamaria et al., 2013);

477 and L. italica in the Mediterranean basin (Hurtado et al. unpublished). The relatively high

478 genetic diversity of the L. exotica clade contrasts with the low diversity observed in its sister

479 lineage $L$. cinerascens (maximum K2P divergence within this species $=2.9 \%$ ), suggesting

480 different evolutionary histories. One evident difference between the two lineages is their

481 geographic distributions. Within our study area alone, L. cinerascens was generally found in

482 relatively colder (mostly temperate) regions, including the northern Yellow Sea, Bohai Sea,

483 Korean Peninsula, and the northern portion of the Japanese archipelago. The range of $L$.

484 cinerascens extends further north into the Kuril Islands (Yin et al., 2013) and the Peter de Great

485 Gulf [i.e., the southernmost part of Russia in the Sea of Japan; (Zenkevich, 1963)]. Although the

486 ranges of L. exotica and L. cinerascens overlap (Figure 1), L. exotica is generally found in

487 warmer (tropical and subtropical) regions. Due to its distribution at higher latitudes, the lower

488 genetic diversity of $L$. cinerascens may reflect a history of recent extinction-expansion events

489 associated with glacial and postglacial cycles. A similar pattern of recognized species of Ligia

490 from high latitudes (at least in the northern hemisphere) harboring low genetic diversity occurs in

491 L. pallasi (Eberl, 2013) and L. oceanica (Raupach et al., 2014).

492 Within the L. exotica clade, Clade B, which is mostly restricted to temperate areas, exhibits

493 comparatively lower genetic diversity (maximum K2P divergence $=2.0 \%$ ) than clades $\mathrm{C}$ and $\mathrm{D}$,

494 which occur in warmer regions. Lineage A was found only in Kanagawa, Japan. The pattern of

495 comparatively lower diversity within Clade B, whose distribution overlaps with part of the range 
496 of L. cinerascens, may also be explained by a history of recent extinction-recolonization events

497 associated with glacial cycles. A similar pattern of reduced genetic diversity at higher latitudes

498 within a recognized coastal isopod species occurs in the northernmost clade of L. occidentalis in

499 California (Eberl et al., 2013), as well as in the northernmost clade of the supralittoral isopod

500 Tylos punctatus, between Southern California and the Baja Peninsula (Hurtado et al., 2014).

501 Temperature also appears to be an important factor determining the distribution of the other $L$.

502 exotica lineages, which are found in warmer waters. Although the northern distribution of $L$.

503 exotica Clade D1 overlaps with the southern range of Clade B in the Yellow Sea, Clade D1 was

504 detected as far south as Taiwan. Clade D2 was found in warmer waters. A haplotype of this

505 clade was observed in the southern coast of Honshu, Japan, which is in a region with warmer

506 water, and was also found in Taiwan and Hawai'i. The only locality where lineage A was found

507 is also in the southern coast of Honshu. Haplogroup "D3" was restricted to warmer waters and

508 reached the southernmost areas (i.e., Cambodia) in what appears to be the native range of the $L$.

509 exotica clade. Sea surface temperature (SST) appears to be an important factor determining the

510 distribution of lineages in L. occidentalis. In this isopod, the geographical limit between two

511 main clades largely reflects the changes in SST that define the Point Conception biogeographical

512 boundary in California (Eberl et al., 2013). Although coastal Ligia are essentially terrestrial and

513 do not venture into open water, SST influences abiotic factors likely important to their survival

514 and reproduction, such as air temperature, sea and land breezes, atmospheric humidity and

515 coastal fog (Eberl et al., 2013).

516 A dynamic past geological history in the Southeast-East Asia region (Ni et al., 2014; Wang,

517 1999) may have contributed to divergences within the L. exotica clade, but we cannot pinpoint

518 specific events. Opportunities for long-standing isolation and differentiation appear to have 
519 occurred in the Japanese archipelago, as suggested by the divergent lineages found in our

520 analyses, and by the reports of several endemic Ligia species to this region (Nunomura, 1979;

521 1983; 1999), discussed above. The highly complex geological history of the Japanese

522 archipelago is considered crucial in the generation and maintenance of the high species diversity

523 and endemism of this region (reviewed in Tojo et al., 2017), considered a global hotspot of

524 biodiversity (Ceballos and Brown, 1995; Conservation International, 2016). Such history has

525 been associated with the presence of multiple highly divergent lineages in the also supralittoral

526 isopod Tylos granulatus (Niikura et al., 2015), the sandy beach amphipod Haustorioides

527 japonicas (Takada et al., 2018), as well as in multiple insects (Tojo et al., 2017). It is important

528 to conduct a thorough examination of Ligia in the Japanese archipelago, which likely will reveal

529 additional diversity and will help to establish the distribution limits of divergent lineages that

530 appear to be endemic to this region (i.e., A and C). Relatively deeper divergences within Clade

531 D also suggest greater opportunities for diversification have occurred in the warmer waters. The

532 island of Taiwan also exhibits high levels of genetic diversity, with the presence of multiple

533 divergent lineages, as observed in the present study and in a previous study based on the

534 Cytochrome Oxidase I (COI) gene (Chang, 2013).

535

5364.4 Evolution of 'invasiveness'

537 Haplotypes found at putative introduced populations are restricted to clade D, and within this 538 clade, to haplogroups D2 and "D3". Therefore, the potential to become invasive appears to be 539 phylogenetically constrained, and to have arisen recently relative to the diversification observed

540 in the L. exotica clade. A similar pattern is observed in the leafmining global fly pest Liriomyza

541 sativae, in which all invasive populations fall within a single clade (Scheffer and Lewis, 2005). 
542 The inherent traits that may enable certain genetic backgrounds of L. exotica to become

543 established at a non-native location might include higher tolerance to environmental stresses

544 associated with the journey and/or the new locality. Tolerance of higher environmental

545 temperatures (at least compared to L. cinerascens and L. exotica clades A and B) might be

546 associated with successful dispersal and establishment. Essentially, all the introduced

547 populations of L. exotica are found in tropical to subtropical locations. Environmental similarity

548 between donor and recipient regions might increase the chance of a successful invasion (Seebens

549 et al., 2013). Nonetheless, lineages of $L$. exotica distributed in similarly warm waters (i.e., C and

550 D1) are not found in introduced populations. Their absence could simply reflect a lack of

551 opportunity to "hitch a ride". This might be a reasonable explanation for clade C, as it is only

552 known from Okinawa, but D1 has a relatively broader distribution in East Asia, that overlaps

553 with that of D2 and "D3".

554 Tolerance to desiccation might also be associated with invasive ability in L. exotica. $L$.

555 exotica individuals were likely unintentionally loaded onto ships along with ballast stones

556 commonly used during the $18^{\text {th }}$ and $19^{\text {th }}$ centuries, and dumped at the destination port (Griffiths

557 et al., 2011; Van Name, 1936). Isopods riding in the holds of ships likely faced limited access to

558 seawater. Low desiccation resistance is a feature of the genus Ligia, constituting one of the

559 factors that constrain its coastal distribution to a very narrow vertical range between the

560 supralittoral and the water line (Carefoot and Taylor, 1995; Hurtado et al., 2010). A superior

561 desiccation resistance and osmoregulation ability compared to L. taiwanensis and/or $L$.

562 cinerascens, which could enhance survival of such journeys, has been reported in $L$. exotica from

563 Taiwan (Tsai et al., 1997; 1998), where clade D occurs. Once in a new harbor, the availability of

564 rocky habitat, similar temperatures to source localities, and high reproductive rates would have 
565 contributed to their successful establishment. Indeed, high reproductive rates have been reported

566 for L. exotica in an introduced Brazilian population (Lopes et al., 2006).

567 Finally, L. exotica do not appear to have evolved traits that enable them to outcompete and 568 displace native Ligia species. In some regions where other Ligia species are widely distributed, 569 establishment of introduced L. exotica populations has failed (e.g., the Mediterranean, Atlantic

570 Europe, the Azores), or only few scattered introduced L. exotica populations have established, 571 mainly in man-made rocky habitats (e.g., Hawaii and the Caribbean). It is possible that the broad 572 distribution of endemic L. occidentalis lineages in the Gulf of California and Pacific coast

573 between central US and southern Mexico precludes the establishment of L. exotica in these 574 regions. In contrast, absence of other Ligia species may have favored the establishment and 575 wide expansion of L. exotica in the US Atlantic coast, the Gulf of Mexico, and the coast between 576 Brazil to northern Argentina.

\section{CONCLUSION}

578 The present study capitalized on a large dataset of 16S rDNA sequences for Ligia specimens 579 from East and Southeast Asia. Addition of de novo sequences from other localities within this 580 region and putative introduced populations around the world, allowed for a broad geographic 581 representation of the widespread $L$. exotica. Phylogenetic analyses revealed that the $L$. exotica 582 clade originated and diversified in East and Southeast Asia, and only members of one of the 583 divergent lineages have spread out of this region recently, suggesting that the potential to

584 become invasive is phylogenetically constrained. Much higher haplotype diversity was observed 585 in East and Southeast Asia, than in the other regions surveyed (Americas, Hawai'i, Africa and 586 India), where only seven $16 \mathrm{~S}$ rDNA haplotypes were detected; which were identical or very 587 closely related to haplotypes from East and Southeast Asia. Multiple geographically distant 
588 introduced populations share the same mitochondrial haplotype, but in the New World at least

589 three haplotypes arrived. This study also revealed interesting biogeographical patterns, such as

590 the reduced genetic diversity at higher latitudes. Our study demonstrates the potential of even

591 modest genetic information collected at broad scales, to substantially improve our understanding

592 on the evolutionary and invasive histories of cryptogenic species.

593

594

\section{ACKNOWLEDGEMENTS}

595 We thank the following individuals and institutions for specimens: Aska Yamaki (Yokohama

596 National University, Japan); Jeng-Di Lee (Institute of Marine Affairs, National Sun Yat-sen

597 University, Kaohsiung, Taiwan); Dr. Ravichandran (Annamalai University, India), Charles

598 Griffiths; Jesser Fidelis de Souza Filho (Museu de Oceanografia/UFPE, Recife, PE, Brazil);

599 Paulo C. Paiva (Departamento de Zoologia, Universidade Federal do Rio de Janeiro, Rio de

600 Janeiro, Brazil); I. Tomasco; D. Macedo; Florida Museum of Natural History.

601

602

603

604

605

606

607

608

609

610

\section{References}

Alfaro, M. E., and M. T. Holder. 2006. The posterior and the prior in Bayesian phylogenetics. Annual Review of Ecology, Evolution, and Systematics 37:19-42. 10.2307/annurev.ecolsys.37.091305.30000003

Banks, N. C., D. R. Paini, K. L. Bayliss, and M. Hodda. 2015. The role of global trade and transport network topology in the human-mediated dispersal of alien species. Ecology Letters 18:188-199. 10.1111/ele.12397

611

612

613

614

615

616

Byers, J. E., R. S. Smith, J. M. Pringle, G. F. Clark, P. E. Gribben, C. L. Hewitt, G. J. Inglis, E. L. Johnston, G. M. Ruiz, J. J. Stachowicz, and M. J. Bishop. 2015. Invasion Expansion: Time since introduction best predicts global ranges of marine invaders. Scientific Reports 5:12436. 10.1038/srep12436

Cardigos, F., F. Tempera, S. Ávila, J. Gonçalves, A. Colaço, and R. S. Santos. 2006. Nonindigenous marine species of the Azores. Helgoland Marine Research 60:160-169. 
617 Carefoot, T. H., and B. E. Taylor. 1995. Ligia: a prototypal terrestrial isopod. Pp. 47-60 in M.

618

619

620

621

622

623

624

625

626

627

628

629

630

631

632

633

634

635

636

637

638

639

640

641

642

643

644 645

646

647

648

649 650

A. Alikhan, ed. Terrestrial Isopod Biology. A.A. Balkema Publishers, Netherlands.

Carlton, J. T. 1987. Patterns of transoceanic marine biological invasions in the pacific ocean. Bulletin of Marine Science 41:452-465.

Carlton, J. T. 1996. Biological invasions and cryptogenic species. Ecological Society of America 77:1653-1655.

Carlton, J. T. 2009. Deep invasion ecology and the assembly of communities in historical time. Pp. 13-56. Biological Invasions in Marine Ecosystems. Springer.

Carlton, J. T., and E. W. Iverson. 1981. Biogeography and natural history of Sphaeroma walkeri Stebbing (Crustacea: Isopoda) and its introduction to San Diego Bay, California. Journal of Natural History 15:31-48.

Castresana, J. 2000. Selection of conserved blocks from multiple alignments for their use in phylogenetic analysis. Molecular Biology and Evolution 17:540-552.

Ceballos, G., and J. H. Brown. 1995. Global patterns of mammalian diversity, endemism, and endangerment. Conservation Biology 9:559-568. 10.1046/j.1523-1739.1995.09030559.x

Chang, W.-C. 2013. Comparison of population genetics of sea slaters (Ligia exotica) in harbor areas and non-harbor areas in Taiwan.National Sun Yat-sen University, Kaohsiung, Taiwan. 66 pp.

Cochard, P.-O., F. Vilisics, and E. Sechet. 2010. Chapter 7.1. Alien terrestrial crustaceans (Isopods and Amphipods). Pp. 81-96 in A. Roques, M. Kenis, D. Lees, C. LopezVaamonde, W. Rabitsch, J.-Y. Rasplus and D. Roy, eds. Alien terrestrial arthropods of Europe, BioRisk 4, Special Issue. Pensoft Publishers, Sofia, Bulgaria.

Conservation International. 2016. The Critical Ecosystem Partnership Fund: Protecting Nature's Hotspots for People and Prosperity. http://www.cepf.net/resources/hotspots/AsiaPacific/Pages/Japan.aspx. Accessed 18 December 2017

Dalens, H. 1993. Two new genera of terrestrial isopods (Crustacea: Isopoda: Oniscidea) from north-western Western Australia. Records of the Western Australia Museum 16:257-267.

Darriba, D., G. L. Taboada, R. Doallo, and D. Posada. 2012. jModelTest2: more models, new heuristics and parallel computing. Nature Methods 9:772.

Eberl, R. 2013. Phylogeography of the high intertidal isopod Ligia pallasii Brandt, 1833 (Isopoda: Oniscidea) from the Aleutian Islands to Monterey Bay. Journal of Crustacean Biology 33:253-264. 10.1163/1937240x-00002131

Eberl, R., M. Mateos, R. K. Grosberg, C. A. Santamaria, L. A. Hurtado, and D. Bellwood. 2013. Phylogeography of the supralittoral isopod Ligia occidentalisaround the Point Conception 
651

652

653

654

655

656

657

658

659

660

661

662

663

664

665

666

667

668

669

670

671

672

673

674

675

676

677 678

679

680

681

682

683

684

marine biogeographical boundary. Journal of Biogeography 40:2361-2372.

$10.1111 / \mathrm{jbi} .12168$

Eldredge, L. G., and C. Smith. 2001. A guidebook of introduced marine species in Hawaii. Bishop Museum and the University of Hawai'i Honolulu, HI

Ferrara, F., and S. Taiti. 1979. A check-list of terrestrial isopods from Africa (south of the Sahara). Monitore Zoologico Italiano. Supplemento 12:89-215.

Fofonoff, P., G. Ruiz, B. Steves, C. Simkanin, and J. Carlton. 2017. National Exotic Marine and Estuarine Species Information System. http://invasions.si.edu/nemesis/. Accessed 13 Nov 2017

Geller, J. B., J. A. Darling, and J. T. Carlton. 2010. Genetic perspectives on marine biological invasions. Annual Review of Marine Science 2:367-393. 10.1146/annurev.marine.010908.163745

Green, A. J. A. 1962. Record of the occurrence in Australia of Ligia exotica Roux (Crustacea, Isopoda, Oniscoidea). Papers and Proceedings of the Royal Society of Tasmania 96:8385.

Greenan, T. M., C. L. Griffiths, and C. A. Santamaria. 2017. Phylogeography and cryptic diversity of intertidal Ligia isopods (Crustacea, Isopoda, Ligiidae) across the southern Africa coastline. PeerJ PrePrints

Griffiths, C., T. Robison, and A. Mead. 2011. The alien and cryptogenic marine crustaceans of South Africa. Pp. 716 in B. S. Galil, P. F. Clark and J. T. Carlton, eds. In the Wrong Place - Alien Marine Crustaceans: Distribution, Biology and Impacts. Springer Netherlands.

Guindon, S., and O. Gascuel. 2003. A simple, fast, and accurate algorithm to estimate large phylogenies by maximum likelihood. Systems Biology 52:696-704.

Holthuis, L. 1949. The Isopoda and Tanaidacea of the Netherlands, including the description of a new species of Omnoria. Zoologische Mededelingen 30:163-190.

Huelsenbeck, J. P., and F. Ronquist. 2001. MrBayes: Bayesian inference of phylogeny. Bioinformatics 17:754-755.

Hurtado, L. A., E. J. Lee, and M. Mateos. 2013. Contrasting phylogeography of sandy vs. rocky supralittoral isopods in the megadiverse and geologically dynamic Gulf of California and adjacent areas. PLoS ONE 8:e67827. 10.1371/journal.pone.0067827

Hurtado, L. A., E. J. Lee, M. Mateos, and S. Taiti. 2014. Global diversification at the harsh sealand interface: mitochondrial phylogeny of the supralittoral isopod genus Tylos (Tylidae, Oniscidea). PLoS One 9:e94081. 10.1371/journal.pone.0094081 
685

686

687

688

689

690

691

692

693

694

695

696

697

698

699

700

701

702

703

704

705

706

707

708

709

710

711

712

713

714

715

716

717

718

719

Hurtado, L. A., M. Mateos, and S. Liu. 2017. Phylogeographic patterns of a lower intertidal isopod in the Gulf of California and the Caribbean and comparison with other intertidal isopods. Ecology and Evolution 7:346-357. 10.1002/ece3.2599

Hurtado, L. A., M. Mateos, G. Mattos, S. Liu, P. A. Haye, and P. C. Paiva. 2016. Multiple transisthmian divergences, extensive cryptic diversity, ocassional long-distance dispersal and biogeographic patterns in a marine coastal isopod with an amphi-American distribution. Ecology and Evolution 6:7794-7808. 10.1002/ece3.2397

Hurtado, L. A., M. Mateos, and C. A. Santamaria. 2010. Phylogeography of supralittoral rocky intertidal Ligia isopods in the pacific region from central California to central Mexico. PLoS One 5:e11633. 10.1371/journal.pone.0011633

Jung, J., H.-S. Eo, H. S. Rho, and W. Kim. 2008. Two genetic lineages of sea slaters, Ligia (Crustacea: Isopoda) in South Korea: a population genetic approach. Molecules and Cells 25:523-530.

Katoh, S. 2013. MAFFT multiple sequence alignment software version 7: Improvements in performance and usability. Molecular Biology and Evolution 30:772-780. 10.1093/molbev/mst010.

Khalaji-Pirbalouty, V., and J.-W. Wägele. 2010. Two new species of Ligia Fabricius, 1798 (Crustacea: Isopoda: Ligiidae) from coasts of the Persian and Aden gulfs. Organisms Diversity \& Evolution 10:135-145.

Kolaczkowski, B., and J. W. Thornton. 2006. Is there a star tree paradox? Molecular Biology and Evolution 23:1819-1823. 10.1093/molbev/ms1059

Kwon, D. H. 1993. Terrestrial isopoda (Crustacea) from Korea. The Korean Journal of Zoology 36:133-158.

Lewis, P. O., M. T. Holder, and K. E. Holsinger. 2005a. Phycas: software for phylogenetic analysis. Available from http://www.phycas.org

Lewis, P. O., M. T. Holder, and K. E. Holsinger. 2005b. Polytomies and Bayesian phylogenetic inference. Systematic Biology 54:241-253. 10.1080/10635150590924208

Lopes, E. R. C., J. R. Blasina, L. F. C. Dumont, and F. D'Incao. 2006. Reproductive biology of Ligia exotica (Crustacea, Isopoda, Ligiidae) in Rio Grande, Rio Grande do Sul State, Brazil. Iheringia Serie Zoologia 96:5-12.

Miller, M. A., W. Pfeiffer, and T. Schwartz. 2010. Creating the CIPRES Science Gateway for inference of large phylogenetic trees. Gateway Computing Environments Workshop (GCE), 2010, 1-8.

Mulaik, S. B. 1960. Contribución Al Conocimiento De Los Isopodos Terrestres De México (Isopoda, Oniscoidea). Sociedad Mexicana de Historia Natural, Mexico. 
720

721

722

723

724

725

726

727

728

729

730

731

732

733

734

735

736

737

738

739

740

741

742

743

744

745

746

747

748

749

750

751

752

753

Ni, G., Q. I. Li, L. Kong, and H. Yu. 2014. Comparative phylogeography in marginal seas of the northwestern Pacific. Molecular Ecology 23:534-548. 10.1111/mec.12620

Niikura, M., M. Honda, and K. Yahata. 2015. Phylogeography of semiterrestrial isopod, Tylos granuliferus, on East Asian coasts. Zoolog Sci 32:105-13. 10.2108/zs140004

Nunomura, N. 1979. Ligia boninensis, a new isopod crustacean from Haha-jima, Bonin Islands, Japan. Bulletin of the Toyama Science Museum 1:37-40.

Nunomura, N. 1983. Studies on the terrestrial isopod crustaceans in Japan. I. Taxonomy of the families Ligiidae, Trichoniscidae and Olibrinidae. Bulletin of the Toyama Science Museum 5:23-68.

Nunomura, N. 1990. Studies on the terrestrial isopod crustaceans in Japan V. Taxonomy of the families Armadillidiidae, Armadillidae and Tylidae, with taxonomic supplements to some other families. Bulletin of the Toyama Science Museum 13:1-58.

Nunomura, N. 1999. Sea shore isopod crustaceans collected from Izu Islands, Middle Japan. Bulletin of the Toyama Science Museum 22:7-38.

Nunomura, N. 2009. Terrestrial isopod crustaceans from Daito Islands, southern Japan. Bulletin of the Toyama Science Museum 32:75-87.

Nylander, J. A., J. C. Wilgenbusch, D. L. Warren, and D. L. Swofford. 2008. AWTY (are we there yet?): a system for graphical exploration of MCMC convergence in Bayesian phylogenetics. Bioinformatics 24:581-583.

Palumbi, S. R. 1996. Nucleic acids II: polymerase chain reaction. In Molecular Systematics, 2nd Edition, D. Hillis, C. Moritz, and B. Mable Eds. Sinauer Press.:205-247.

Podsiadlowski, L., and T. Bartolomaeus. 2005. Organization of the mitochondrial genome of mantis shrimp Pseudosquilla ciliata (Crustacea: Stomatopoda). Marine Biotechnology 7:618-624. 10.1007/s10126-005-0017-8

Rambaut, A., M. A. Suchard, D. Xie, and A. J. Drummond. 2014. Tracer v1.6. Available from http://beast.bio.ed.ac.uk/Tracer

Raupach, M. J., O. R. P. Bininda-Emonds, T. Knebelsberger, S. Laakmann, J. Pfaender, and F. Leese. 2014. Phylogeographical analysis of Ligia oceanica (Crustacea: Isopoda) reveals two deeply divergent mitochondrial lineages. Biological Journal of the Linnean Society 112:16-30. 10.1111/bij.12254

Richardson, H. 1905. Monograph on the Isopods of North America. Government Printing Office, Washington.

Roman, M.-L. 1977. Les Oniscoides halophiles de Madagascar (Isopoda, Oniscoidea). Beaufortia 26:107-152. 
754

755

756

757

758

759

760

761

762

763

764

765

766

767

768

769

770

771

772

773

774

775

776

777

778

779

780

781

782

783

784

785

786

787

788

Ronquist, F., and J. P. Huelsenbeck. 2003. MrBayes 3: Bayesian phylogenetic inference under mixed models. Bioinformatics 19:1572-1574.

Ronquist, F., M. Teslenko, P. van der Mark, D. L. Ayres, A. Darling, S. Höhna, B. Larget, L. Liu, M. A. Suchard, and J. P. Huelsenbeck. 2012. MrBayes 3.2: efficient Bayesian phylogenetic inference and model choice across a large model space. Systematic Biology 61:539-542. 10.1093/sysbio/sys029

Roux, P. 1828. Crustacés de la Méditerranée et de son littoral. Levrault, Marseille.

Santamaria, C. A., E. T. Bischoff III, M. Aye, K. W. Phillips, and V. Overmeyer. 2017a. First record of the Ligia baudiniana species complex in the American Gulf of Mexico Coastline, as confirmed by morphological and molecular approaches. F1000Research $6: 1602$.

Santamaria, C. A., J. K. Bluemel, N. Bunbury, and M. Curran. 2017b. Cryptic biodiversity and phylogeographic patterns of Seychellois Ligia isopods. PeerJ 5:e3894.

Santamaria, C. A., M. Mateos, T. J. DeWitt, and L. A. Hurtado. 2016. Constrained body shape among highly genetically divergent allopatric lineages of the supralittoral isopod Ligia occidentalis (Oniscidea). Ecology and Evolution10.1002/ece3.1984

Santamaria, C. A., M. Mateos, and L. A. Hurtado. 2014. Diversification at the narrow sea-land interface in the Caribbean: phylogeography of endemic supralittoral Ligia isopods. Frontiers in Ecology and Evolution 2:2-42. 10.3389/fevo.2014.00042

Santamaria, C. A., M. Mateos, S. Taiti, T. J. DeWitt, and L. A. Hurtado. 2013. A complex evolutionary history in a remote archipelago: phylogeography and morphometrics of the Hawaiian endemic Ligia isopods. PLoS One 8:e85199. 10.1371/journal.pone.0085199

Say, T. 1818. An account of the Crustacea of the United States. Journal of Academy of Natural Science Philadelphia 1:445-458.

Scheffer, S. J., and M. L. Lewis. 2005. Mitochondrial phylogeography of vegetable pest Liriomyza sativae (Diptera: Agromyzidae): divergent clades and invasive populations. Annals of the Entomological Society of America 98:181-186.

Schmalfuss, H. 2003. World catalog of terrestrial isopods (Isopoda: Oniscidea). Stuttgarter Beitrage zur Naturkunde Serie A 654:1-341.

Schultz, G. A. 1977. Terrestrial isopod crustaceans (Oniscoidea) from St. Catherines Island, Georgia. Georgia Journal of Science: Official Publication of the Georgia Academy of Science. 35:151-158.

Schultz, G. A., and C. Johnson. 1984. Terrestrial isopod crustaceans from Florida (Oniscoidea). Tylidae, Ligiidae, Halophilosciidae, Philosciidae, and Rhyscotidae. Journal of Crustacean Biology 4:154-171. 
789

790

791

792

793

794

795

796

797

798

799

800

801

802

803

804

805

806

807

808

809

810

811

812

813

814

815

816

817

818

819

820

821

822

Seebens, H., M. T. Gastner, and B. Blasius. 2013. The risk of marine bioinvasion caused by global shipping. Ecology Letters 16:782-790. 10.1111/ele.12111

Stamatakis, A. 2014. RAxML version 8: a tool for phylogenetic analysis and post-analysis of large phylogenies. Bioinformatics 30:1312-1313. 10.1093/bioinformatics/btu033

Sukumaran, J., and M. T. Holder. 2010. DendroPy: a Python library for phylogenetic computing. Bioinformatics 26:1569-1571.

Suzuki, Y., G. V. Glazko, and M. Nei. 2002. Overcredibility of molecular phylogenies obtained by Bayesian phylogenetics. Proceedings of the National Academy of Sciences 99:1613816143. 10.1073/pnas.212646199

Swofford, D. L. 2002. PAUP*. Phylogenetic analysis using Parsimony (*and other methods). Version 4. Sinauer Associates, Sunderland, Massachusetts. Sinauer Associates, Sunderland, Massachusetts

Taiti, S. 2014. The terrestrial Isopoda (Crustacea, Oniscidea) of the Maldives. Tropical Zoology 27:9-33.

Taiti, S., M. A. Arnedo, S. E. Lew, and G. K. Roderick. 2003. Evolution of terrestriality in Hawaiian species of the genus Ligia. Crustaceana Monographs 2:85-102.

Takada, Y., K. Sakuma, T. Fujii, and S. Kojima. 2018. Phylogeography of the sandy beach amphipod Haustorioides japonicus along the Sea of Japan: Paleogeographical signatures of cryptic regional divergences. Estuarine, Coastal and Shelf Science 200:19-30.

Talavera, G., and J. Castresana. 2007. Improvement of phylogenies after removing divergent and ambiguously aligned blocks from protein sequences alignments. Systematic Biology 56:564-577.

Tojo, K., K. Sekiné, M. Takenaka, Y. Isaka, S. Komaki, T. Suzuki, and S. D. Schoville. 2017. Species diversity of insects in Japan: Their origins and diversification processes. Entomological Science 20:357-381. 10.1111/ens.12261

Tsai, M.-L., C.-F. Dai, and H.-C. Chen. 1997. Responses of two semiterrestrial isopods, Ligia exotica and Ligia taiwanensis (Crustacea) to osmotic stress. Comparative Biochemistry and Physiology A 118:141-146.

Tsai, M.-L., C.-F. Dai, and H.-C. Chen. 1998. Desiccation resistance of two semiterrestrial isopods, Ligia exotica and Ligia taiwanensis (Crustacea) in Taiwan. Comparative Biochemistry and Physiology Part A 119:361-367.

Tsang, L. M., K. Y. Ma, S. T. Ahyong, T. Y. Chan, and K. H. Chu. 2008. Phylogeny of Decapoda using two nuclear protein-coding genes: origin and evolution of the Reptantia. Molecular Phylogenetics and Evolution 48:359-368. Doi 10.1016/J.Ympev.2008.04.009 
823 Van Name, W. G. 1936. The American land fresh-water isopod Crustacea. Bulletin of the $824 \quad$ American Museum of Natural History 71:44-46.

825 Wang, P. 1999. Response of Western Pacific marginal seas to glacial cycles: paleoceanographic 826 and sedimentological features. Marine Geology 156:5-39. 10.1016/S00253227(98)00172-8

828

829

830

831

832

833

834

835

836

837

838

839

840

841

842

843

844

845
Wilgenbusch, J. C., D. L. Warren, and D. L. Swofford. 2004. AWTY: a system for graphical exploration of MCMC convergence in Bayesian phylogenetic inference. Available from http://ceb.csit.fsu.edu/awty

Yang, Z., and B. Rannala. 2005. Branch-length prior influences Bayesian posterior probability of phylogeny. Systematic Biology 54:455-470. 10.1080/10635150590945313

Yang, Z. H. 2006. Computational Molecular Evolution. Oxford University Press, New York, NY.

Yin, J., D. Pan, C. He, A. Wang, J. Yan, and H. Sun. 2013. Morphological and molecular data confirm species assignment and dispersal of the genus Ligia (Crustacea: Isopoda: Ligiidae) along northeastern coastal China and East Asia. Zoological Journal of the Linnean Society 169:362-376. 10.1111/zoj.12068

Zenkevich, L. A. 1963. Biology of the seas of the U.S.S.R. George Allen \& Unwin Ltd., London.

Zwickl, D. J. 2006. Genetic algorithm approaches for the phylogenetic analysis of large biological sequences datasets under the maximum likelihood criterion. The University of Texas at Austin, 


\section{Figure Legends}

847 Figure 1. Sampled localities in (A) the global range and (B) Asia. Circles represent L. exotica;

848 squares (gray) represent L. cinerascens. Colors correspond with lineages shown in Figures 2 and

849 3. Map source: Administrative Units (admin.shp). Edition 10.1. ArcWorld Supplement, 2012.

850 Basemap created with ArcGIS. Version 10.3 Redlands, CA: Esri, 2014.

851

852 Figure 2. Bayesian majority consensus tree of Ligia samples from localities in Figure 1. The

853 tree was obtained by MrBayes for 16S rDNA (model GTR $+\Gamma$ ), and rooted with L. cinerascens.

854 Letters denote four major clades (i.e., A, B, C, and D) of L. exotica and three groups of

855 haplotypes (i.e., D1, D2, and "D3") of clade D. Clade colors correspond to Figures 1 and 3.

856 Numbers in boxes indicate clade support value ranges for each method (bootstrap proportions

857 and Bayesian posterior probabilities) for the $16 \mathrm{~S}$ rDNA dataset (black font) and the $16 \mathrm{~S}+12 \mathrm{~S}$

858 rDNA dataset (red font). Each range reflects pooled values obtained under different substitution

859 models (e.g., GTR $+\Gamma$, $\mathrm{HKY}+\mathrm{I}+\Gamma$, and TPM2uf $+\mathrm{I}+\Gamma$ ) in corresponding program. An asterisk

860 indicates support was equal or greater than $98 \%$. The triangles denote new haplotypes that have

861 not been reported in the previous studies of Jung et al. (2008) and Yin et al. (2013). Stars,

862 squares, and circles denote 16S rDNA haplotypes for which one or more individual was

863 examined for the $12 \mathrm{~S} \mathrm{rDNA}$ and/or the $\mathrm{NaK}$ gene. ${ }^{\wedge}$ indicates specimen from Taiwan for which

864 we were only able to sequence the $12 \mathrm{~S}$ rDNA gene.

865

866 Figure 3. Strict (unrooted) consensus of the 18 most parsimonious trees depicting the

867 relationships among haplotypes in the clade D of L. exotica. Ambiguous character optimization

868 was achieved by the accelerated transformation (ACCTRAN) algorithm. Slashes indicate the 
869 number of parsimony steps. The branch lengths within each haplogroup (i.e., D1, D2, and "D3”)

870 reflect the number of base substitutions. The numbers near the slashes correspond to the number

871 of parsimony steps. Localities where each haplotype was found are listed next to the circles.

872 Localities in bold are those outside the putative native range. Underlined locality label denotes

873 uncertainty regarding its native vs. non-native status (see text). ${ }^{\wedge}$ indicates specimen from

874 Taiwan for which we were only able to sequence the 12S rDNA gene (see Table S1).

875 


\section{Table $\mathbf{1}$ (on next page)}

Genetic divergences among major lineages within $L$. exotica and $L$. cinerascens

Conservative estimates of evolutionary divergence among major lineages within L. exotica and $L$. cinerascens, as measured by percent Kimura-2-parameter distances. Lower matrix: distance range. Upper matrix: average distance. Values on diagonal show minimum and maximum within-clade divergence. Empty cells: no ranges available because selected clade was represented by a single sample. 
1 Table 1. Conservative estimates of evolutionary divergence among major lineages within L. exotica and L. cinerascens, as measured by percent Kimura-2parameter distances. Lower matrix: distance range. Upper matrix: average distance. Values on diagonal show minimum and maximum within-clade divergence. Empty cells: no ranges available because selected clade was represented by a single sample.

\begin{tabular}{|c|c|c|c|c|c|}
\hline & 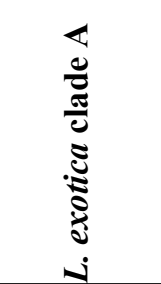 & 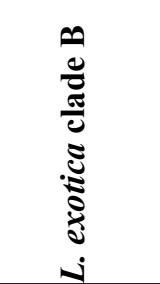 & 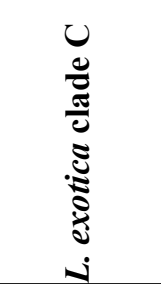 & 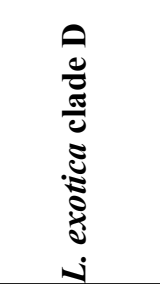 & 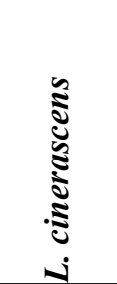 \\
\hline L. exotica clade A & - & 11.5 & 12.5 & 10.5 & 10.4 \\
\hline L. exotica clade B & $11.1-12.1$ & $0.2-2.0$ & 8.8 & 10.0 & 11.7 \\
\hline L. exotica clade $\mathrm{C}$ & $11.9-13.2$ & $7.3-10.8$ & 6.3 & 7.6 & 13.6 \\
\hline L. exotica clade D & $9.8-11.1$ & 8.3-11.6 & $6.7-9.2$ & $0.2-4.6$ & 13.0 \\
\hline L. cinerascens & $9.4-11.0$ & $10.8-13.1$ & $12.3-15.0$ & $11.6-14.9$ & $0.1-2.9$ \\
\hline
\end{tabular}


Figure 1

Sampled localities

Sampled localities in (A) the global range and (B) Asia. Dots represent $L$. exotica; squares (gray) represent $L$. cinerascens. Colors correspond with lineages shown in Figure 2. Map source: Administrative Units (admin.shp). Edition 10.1. ArcWorld Supplement, 2012. Basemap created with ArcGIS. Version 10.3 Redlands, CA: Esri, 2014.

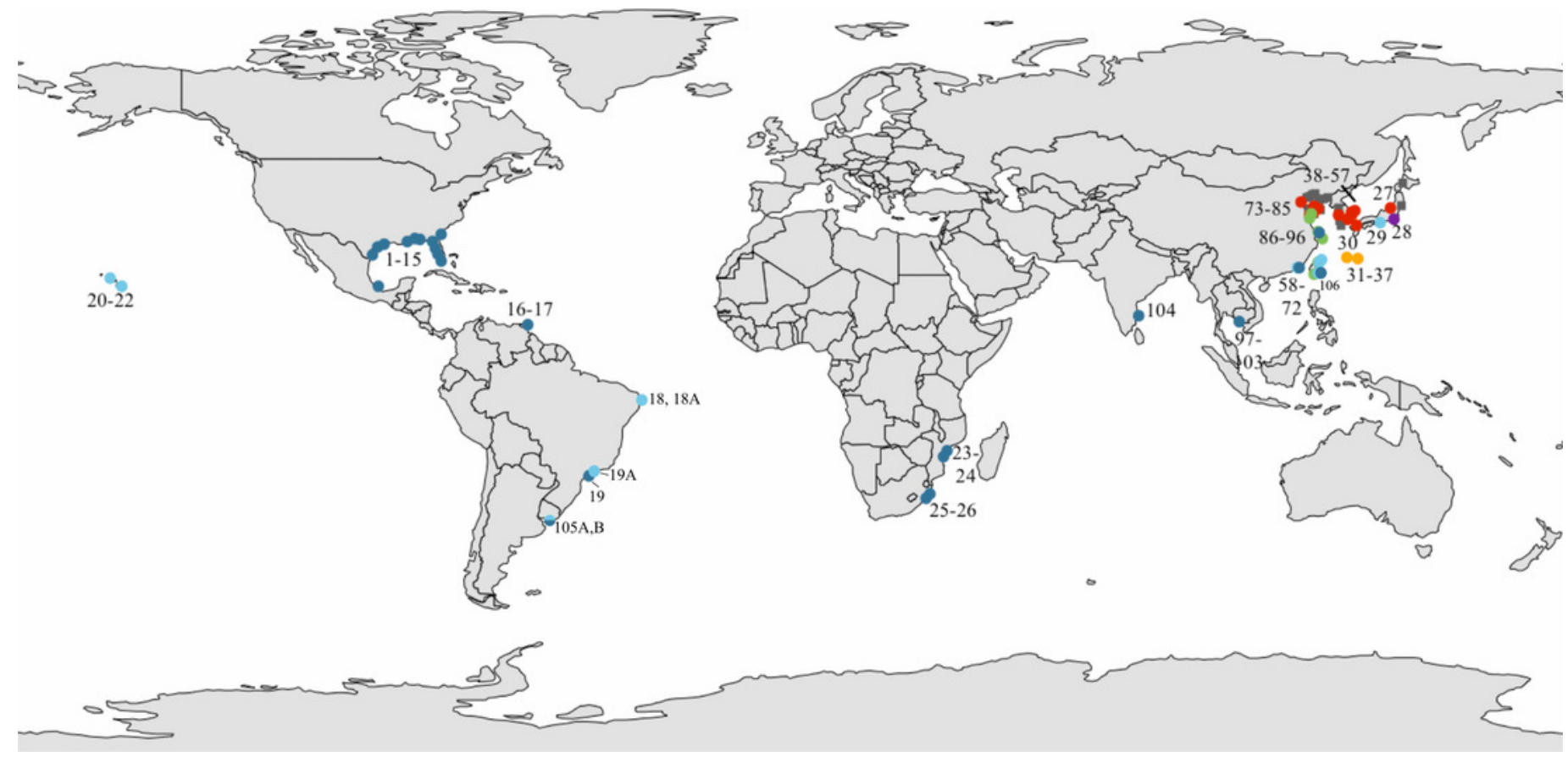




\section{Figure 2 (on next page)}

Bayesian majority consensus tree of Ligia samples from localities in Figure 1

The tree was obtained by MrBayes for $16 \mathrm{~S}$ rDNA (model GTR $+\Gamma$ ), and rooted with $L$.

cinerascens. Letters denote four major clades (i.e., A, B, C, and D) of L. exotica and three groups of haplotypes (i.e., D1, D2, and "D3") of clade D. Clade colors correspond to Figures 1 and 3. Numbers in boxes indicate clade support value ranges for each method (bootstrap proportions and Bayesian posterior probabilities) for the 16S rDNA dataset (black font) and the 16S+12S rDNA dataset (red font). Each range reflects pooled values obtained under different substitution models (e.g., $\mathrm{GTR}+\Gamma, \mathrm{HKY}+\mathrm{I}+\Gamma$, and TPM2Uf $+\mathrm{I}+\Gamma$ ) in corresponding program. An asterisk indicates support was equal or greater than $98 \%$. The triangles denote new haplotypes that have not been reported in the previous studies of Jung et al. (2008) and Yin et al. (2013). Stars, squares, and circles denote 165 rDNA haplotypes for which one or more individual was examined for the $12 \mathrm{~S}$ rDNA and/or the NaK gene. ${ }^{\wedge}$ indicates specimen from Taiwan for which we were only able to sequence the $12 \mathrm{~S}$ rDNA gene. 
Node Support Key 16:Frît: RaxML, Garli, PhyML MrBayes,Phycas

16S rDNA + RaxML, Garli, PhyML 12S rDNA: MrBayes, Phycas

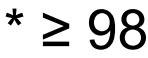

$\Delta$ new 16S haplotype

-16S \& 12S

-16S, 12S \& NaK

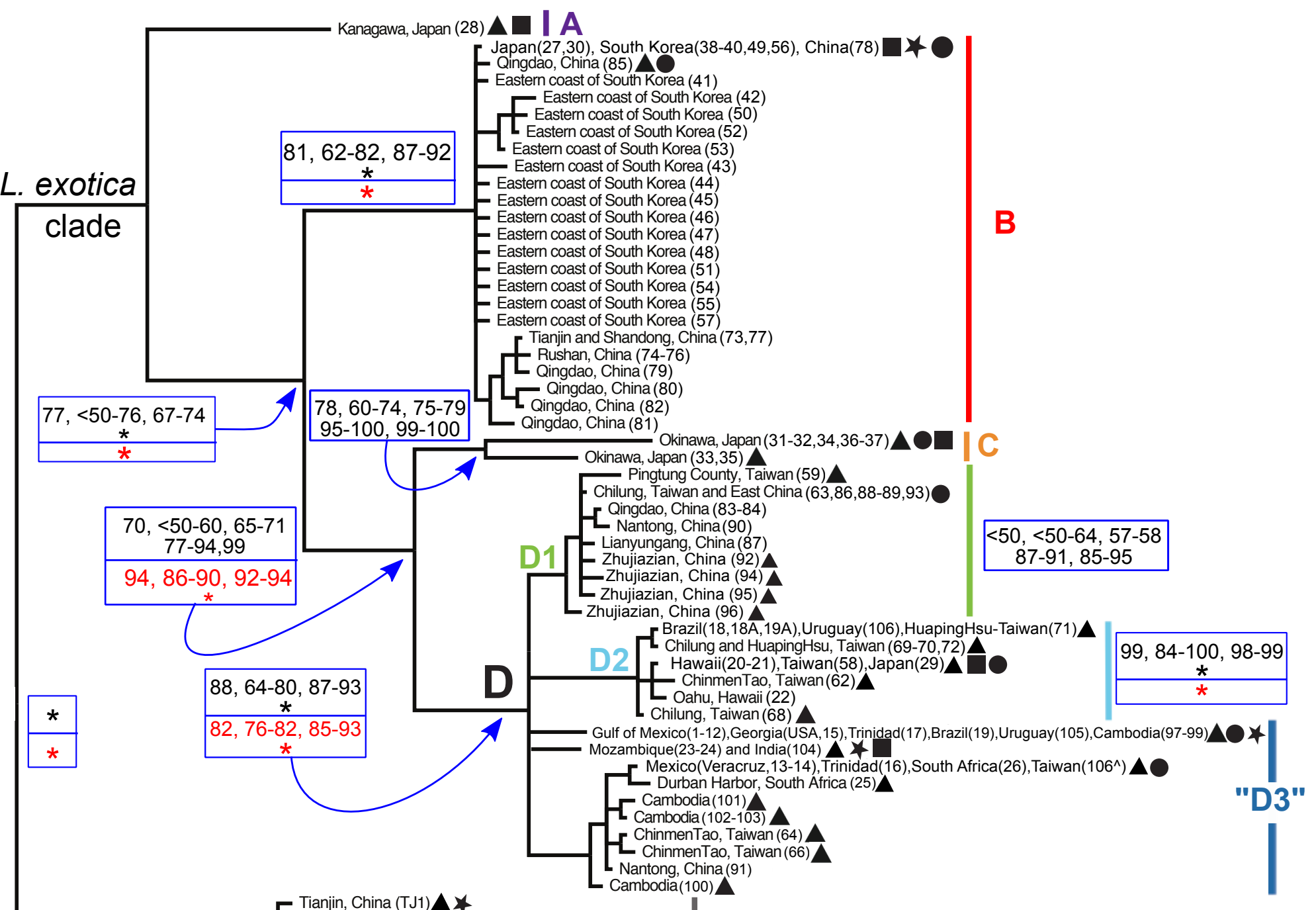

L. cinerascens $\quad L$ Western coast of South Korea

- Western coast of South Korea

- Western coast of South Korea

- Western coast of South Korea

$-\leftarrow$ Western coast of South Korea

- Western coast of South Korea

- Western coast of South Korea and Japan

- Western coast of South Korea

Northeast and East China

Liaoning, China

L Dalian, China

Liaoning and Shandong, China

L Liaoning and Shandong, China

Huludao, China 


\section{Figure $\mathbf{3}$ (on next page)}

Haplotype network of clade D

Strict (unrooted) consensus of the 18 most parsimonious trees depicting the relationships among haplotypes in the clade $D$ of $L$. exotica. Ambiguous character optimization was achieved by the accelerated transformation (ACCTRAN) algorithm. Slashes indicate the number of parsimony steps. The branch lengths within each haplogroup (i.e., D1, D2, and "D3") reflect the number of base substitutions. The numbers near the slashes correspond to the number of parsimony steps. Localities where each haplotype was found are listed next to the circles. Localities in bold are those outside the putative native range. Underlined locality label denotes uncertainty regarding its native vs. non-native status (see text). ${ }^{\wedge}$ indicates specimen from Taiwan for which we were only able to sequence the $12 \mathrm{~S}$ rDNA gene (see Table S1). 


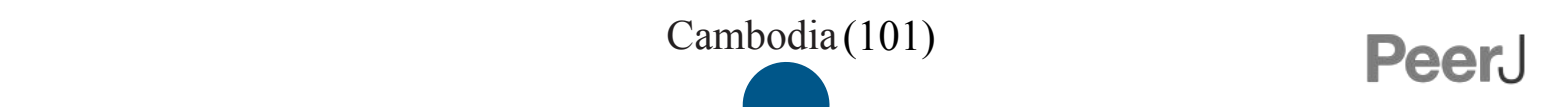

Durban Harbor, South Africa (25)

(3)

Mexico (Veracruz, 13-14) Trinidad (Chaguaramas Bay, 16), South Africa

(Blue Lagoon, 26) Taiwan (Orchid Is., 106^)

Cambodia (100)

Mozambique (Vilanhulos,

23, Beira, 24) and

India (Parangipetta, 104

Gulf of Mexico (1-12), Georgia (USA, 15),

Trinidad (Chaguaramas Bay, 17), Brazil (Ilha Grande, 19),

Uruguay (105)

and Cambodia (97-99)

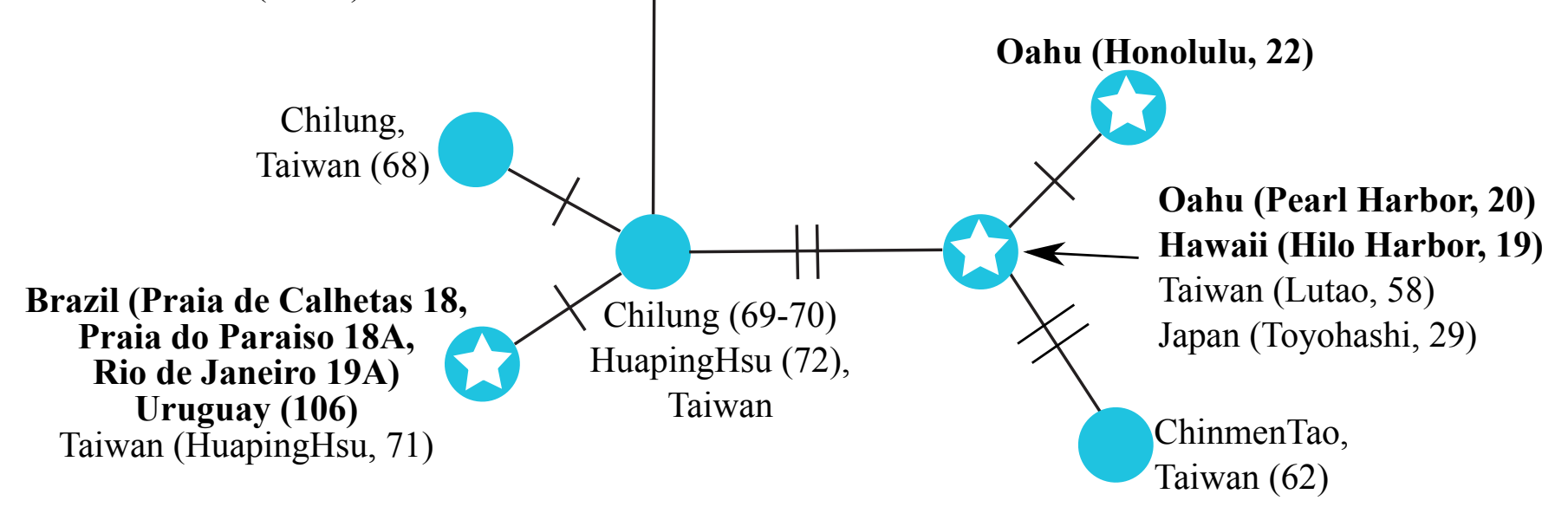

China (Zhujiajian,
86,93, Jiangsu, 88) Lianyungang, China (87)

ChinmenTao,
Taiwan $(61,66) \quad$ Zhujia- $\quad \begin{aligned} & \text { Zhujiazian, } \\ & \text { China (92) }\end{aligned}$ Zhujiazian,
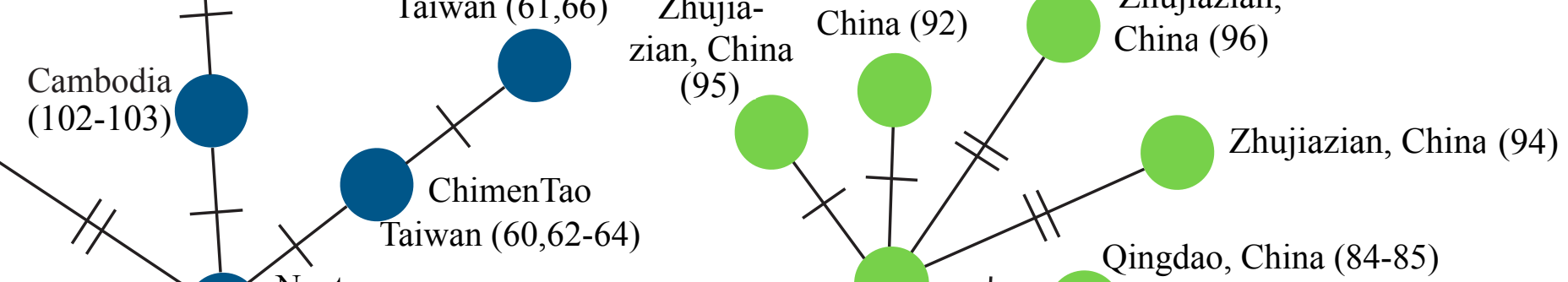

Taiwan (Chilung, 67) $\equiv$

Qingdao, China (84-85)
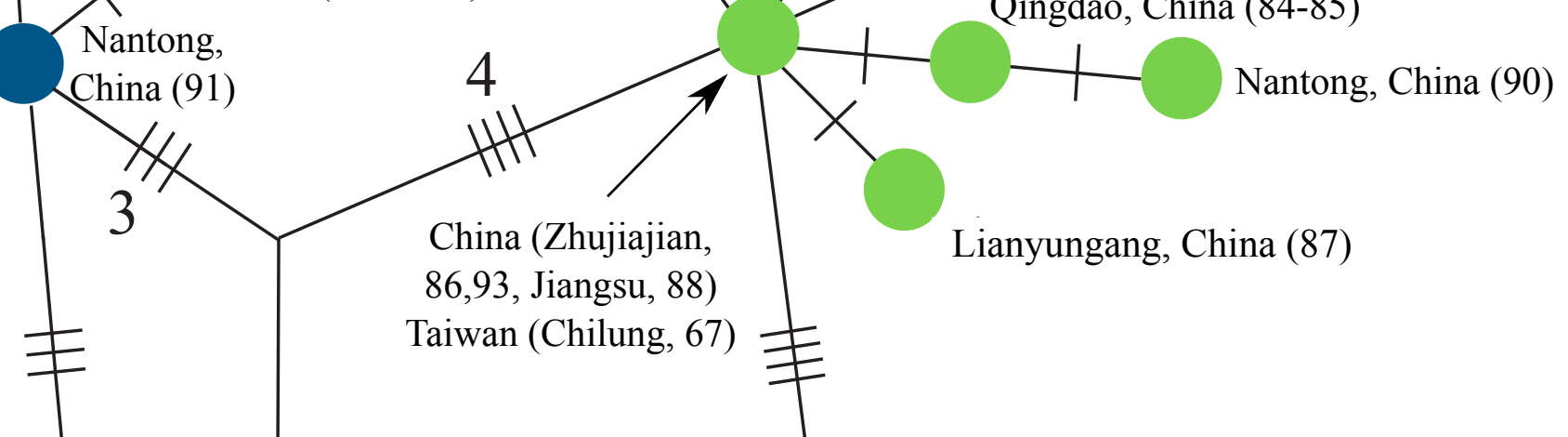

19),

9 事

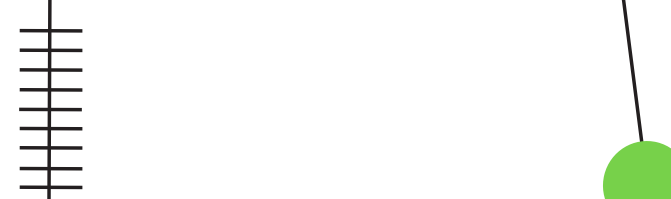

Pintung County, Taiwan ( 59)

Oahu (Honolulu, 22)

D2

"D3"

岁 Putative

Non-native 